\title{
Docetaxel, oxaliplatin, leucovorin, and 5-fluorouracil (FLOT) as preoperative and postoperative chemotherapy compared with surgery followed by chemotherapy for patients with locally advanced gastric cancer: a propensity score-based analysis
}

This article was published in the following Dove Press journal: Cancer Management and Research

\author{
Keshen Wang' \\ Yanxian Ren' \\ Zhijian $\mathrm{Ma}^{2}$ \\ Fan $\mathrm{Li}^{1}$ \\ Xiaocheng Cheng' \\ Jingying Xiao' \\ Shuze Zhang' \\ Zeyuan Yu' \\ Hanteng Yang' \\ Huinian Zhou ${ }^{1,2}$ \\ Yuming $\mathrm{Li}^{1,2}$ \\ Hongbin Liu $^{3}$ \\ Zuo-Yi Jiao',2
}

'Department of General Surgery, Lanzhou University Second Hospital, Lanzhou, Gansu 730010, People's Republic of China;

${ }^{2}$ Cui-ying Experimental Center, Lanzhou University Second Hospital, Lanzhou,

Gansu 730010, People's Republic of China; ${ }^{3}$ Department of General Surgery, The 940th Hospital of Joint Logistics Support Force of People's Liberation Army, Lanzhou 730050, People's Republic of China

\begin{abstract}
Introduction: Docetaxel, oxaliplatin, leucovorin, and 5-fluorouracil (FLOT) may improve overall survival (OS) in patients with locally advanced gastric cancer (LAGC); however, evidence for its use as a standard treatment has not been established in China. The aim of this study was to investigate the effectiveness, safety, and feasibility of the FLOT regimen as neoadjuvant chemotherapy in Chinese patients with resectable LAGC.

Methods: We conducted an observational study to compare the effectiveness of FLOT regimen consisting of docetaxel $\left(60 \mathrm{mg} / \mathrm{m}^{2}\right)$, oxaliplatin $\left(85 \mathrm{mg} / \mathrm{m}^{2}\right)$, leucovorin $\left(200 \mathrm{mg} / \mathrm{m}^{2}\right)$, and 5-fluorouracil $\left(2,600 \mathrm{mg} / \mathrm{m}^{2}\right.$ as a $24 \mathrm{hr}$ infusion), all given on day 1 and administered every 2 weeks versus initial surgery followed by chemotherapy in patients with clinical T3-4 LAGC. OS was compared by using the Cox proportional hazards regression model and the KaplanMeier curve adjusted by inverse probability of treatment weighting (IPTW) and propensity scorematched (PSM) analysis. In addition, we performed subgroup analyses to determine the effectiveness of the FLOT regimen in clinically relevant patient subsets.

Results: Overall, 47 patients who received initial FLOT chemotherapy and 269 patients who received initial surgery were enrolled in this study. In the PSM analysis, the FLOT-first group showed favorable OS compared with the surgery-first group (41 vs 41 [HR, 0.416; 95\% CI, $0.218-0.794 ; P=0.008]$ ), and 3-year survival rates were $58.7 \%$ and $30.9 \%$ in the FLOT-first group and surgery-first group, respectively. IPTW analysis showed similar results. However, the effect of FLOT was low (HR, 0.868; $95 \mathrm{CI} \%, 0.215-3.504)$ in patients without lymph node metastasis.
\end{abstract}

Conclusion: Our study suggests that preoperative FLOT chemotherapy is safe and feasible. In terms of OS, FLOT may be superior to initial surgery followed by chemotherapy in reducing morbidity with resectable LAGC.

Keywords: gastric cancer, preoperative chemotherapy, propensity score, FLOT, prognosis

\section{Introduction}

Gastric cancer (GC) is the fifth most common malignancy worldwide and the third leading cause of cancer-related mortality. ${ }^{1}$ The mortality rate for GC has continued to increase in the past decade and the high mortality rate reflects the prevalence of advanced stage at presentation, especially in China. ${ }^{2}$ Currently, for patients with pT1-
Department of General Surgery and

Cuiying Experimental Center, Lanzhou

University Second Hospital, No.82

Cuiyingmen, Cheng-Guan District,

Lanzhou, Gansu 730010, People's

Republic of China

Tel +860931 8943707

Email jiaozy@lzu.edu.cn 
stage GC, radical surgery (including endoscopic mucosal and submucosal dissection) can be performed to peruse curative outcome, and the postoperative 5-year survival rate can reach 85-95\%. However, in China, patients with advanced gastric cancer (AGC) account for nearly $80 \%$ of the total number, and the postoperative 5-year survival rate remains only $30-50 \%$. This situation indicates that for most patients with AGC, even if an expanded scope of surgical resection and lymph node dissection were performed, surgery alone or surgery plus chemotherapy cannot achieve the goal of radical cure. Therefore, the concept of preoperative chemotherapy, also known as neoadjuvant chemotherapy (NACT), was proposed to improve the radical resection rate and control preoperative micrometastasis.

In the early $1990 \mathrm{~s}^{3}$ the literature reported the application of neoadjuvant chemotherapy in patients with resectable GC, mostly regimens based on 5-fluorouracil, combined with adriamycin (ADM), mitomycin (MMC), and cisplatin (DDP). In these studies, the median survival time of neoadjuvant chemotherapy was 15-40 months, which was significantly better than that of patients who received surgery alone ${ }^{4-8}$ In 2006, the MAGIC study (a Phase III, randomized, controlled study) conducted a trial of patients who received three cycles of epirubicin, cisplatin, and fluorouracil (ECF) as chemotherapy before and after surgery and the control group who received surgery alone, ${ }^{9}$ and found that the overall survival (OS) rate of the perioperative chemotherapy group was significantly better than that of the surgery-alone group (36\% vs $23 \%$, HR, $0.75 ; 95 \%$ CI, 0.60-0.93; $P=0.0009)$. In another multicenter randomized controlled trial from France (FNCLCC ACCORD 07-FFCD 9703), preoperative application of 5-FU and cisplatin versus surgery alone resulted in OS rates of $38 \%$ and $24 \%$, respectively $(P=0.02)$ and disease-free survival rates of $34 \%$ and $19 \%$, respectively $(P=0.003) .{ }^{10}$ Furthermore, the results of the Phase II/III multicenter randomized controlled trial (FLOT4-AIO) showed that the FLOT regimen was significantly superior to the ECF/ECX regimen of the MAGIC trial in terms of OS (HR, 0.0.77; 95\% CI, 0.63-0.94; $P=0.012) .{ }^{11}$ The positive impact of preoperative chemotherapy on survival in patients with resectable AGC has been confirmed by many meta-analyses, ${ }^{12,13}$ although there is no consensus as to the best regimen.

Due to the lack of adequate treatment experience and because the efficacy of NACT has not been clearly verified for Chinese patients, most practitioners still prefer initial surgery once the diagnosis was made. In addition, no study to date has directly compared the efficacy of FLOT as NACT regimen with that of initial surgery followed by adjuvant chemotherapy. Therefore, we designed this study to investigate the relative benefit of FLOT regimen as NACT compared with initial surgery for Chinese patients with resectable locally advanced gastric cancer (LAGC) and investigated the subgroup of patients who would be having better benefits.

\section{Methods}

\section{Patients enrollment}

From January 2013 to December 2017, clinical data of 341 patients with LAGC who underwent radical gastrectomy were collected at the Department of General Surgery, Lanzhou University Second Hospital.

The eligibility criteria were as follows: 1) preoperative cT3-4; 2) histologically proven adenocarcinoma; 3) underwent D2 or extended D2 lymphadenectomy; 4) complete clinical records; 5) no distant metastasis such as liver, lung or bone; 6) <75 years old; and (7) Eastern Cooperative Oncology Group (ECOG) score 0-2 points.

The exclusion criteria were as follows: 1) previous history of other cancers; 2) gastric stump cancer; and 3) received preoperative radiotherapy. Ultimately, a total of 316 patients who met the criteria were included in this study, representing $92.7 \%$ of the total number of patients with LAGC during the same period. The requirement to obtain written informed consent from patients was waived because of the retrospective nature of this study. The study was conducted in accordance with the Declaration of Helsinki and approved by the Ethics Committee of Lanzhou University Second Hospital.

\section{Treatment}

Patients in the NACT group received at least 1 week of preoperative chemotherapy with the FLOT regimen consisting of docetaxel $\left(60 \mathrm{mg} / \mathrm{m}^{2}\right)$, oxaliplatin $\left(85 \mathrm{mg} / \mathrm{m}^{2}\right)$, leucovorin $\left(200 \mathrm{mg} / \mathrm{m}^{2}\right)$, and 5 -fluorouracil $\left(2,600 \mathrm{mg} / \mathrm{m}^{2}\right.$ as a $24 \mathrm{hr}$ infusion), all given on day 1 . This procedure was performed every 2 weeks and surgery was followed 3 weeks after chemotherapy was completed. Patients underwent imaging evaluation (computed tomography [CT] or magnetic resonance imaging [MRI]) after receiving FLOT neoadjuvant. If the tumor resolved, the patients finished three cycles of preoperative chemotherapy. If the imaging evaluation revealed the chemotherapy ineffective or the tumor progressed, surgery was performed directly. Patients 
in the two groups all received at least one cycle of adjuvant chemotherapy after surgery, and we preferred to use FLOT. If the FLOT regimen was not tolerated due to toxic reaction, then it was replaced by XELOX (oxaliplatin $130 \mathrm{mg} / \mathrm{m}^{2}$ on day 1 ; xeloda $1,000 \mathrm{mg} / \mathrm{m}^{2}$ twice a day, on day $1-14$ ), SOX (oxaliplatin $130 \mathrm{mg} / \mathrm{m}^{2}$ on day 1; tegafur $40 \mathrm{mg} / \mathrm{m}^{2}$ twice a day, on day 1-14), or FOLFOX6 (oxaliplatin $85 \mathrm{mg} / \mathrm{m}^{2}$, leucovorin $200 \mathrm{mg} / \mathrm{m}^{2}$ on, and 5-fluorouracil $2,600 \mathrm{mg} / \mathrm{m}^{2}$ ) regimens. All patients in our study underwent total, subtotal, or distal gastrectomy based on the primary tumor size and location. The strategy for lymph node dissection was taken by standard D2 or extended D2 lymphadenectomy.

\section{Data collection}

After reviewing medical records, we obtained data on age, sex, time of diagnosis, tumor location, preoperative ECOG score, clinical TNM stage, Lauren classification, style of operation, regimen of adjuvant chemotherapy, depth of tumor invasion, and number of positive lymph nodes in all patients. Depth of tumor invasion was utilized to stage tumors according to the 7 th edition AJCC guidelines. ${ }^{14}$ The primary endpoint in this study was OS, which was calculated from the time of the any form of treatment since diagnosis to the date of death (for any reason) or the most recent follow-up. The secondary endpoint was response, which was evaluated by CT scan in each cycle according to RECIST criterion $\mathrm{v} 1.1$, and compared with the baseline CT scan performed before treatment.

\section{Statistical analysis}

Associations between treatment modality and patients' demographic, clinical, and facility characteristics were assessed using Pearson $\chi^{2}$ or Fisher's exact test for categorical data and independent-sample $t$ test for continuous variables, respectively. To reduce bias from nonrandom treatment assignments, two models of the association between OS and treatment modality based on propensity score analysis were constructed: propensity score-matched (PSM) and weighting by inverse probability of treatment (IPTW). The propensity score analysis of receipt of NACT was used to take into account all baseline covariates into a nonparsimonious manner and was constructed using a multivariable logistic regression model, which contained age, gender, tumor location, clinical TNM stage, Lauren classification, and year of diagnosis. The Hosmer and Lemeshow goodness-of-fit statistics and the area under the receiver operating characteristic curve (AUC) were calculated to evaluate the adequacy of the model.

For the matched-patient analysis, patients treated with NACT were matched 1:1 to patients who received initial surgery on propensity score with a caliper of 0.05 . We also assessed the heterogeneity of treatment effects with tests of interaction and subgroup analysis that explored the effect of age, gender, clinical TNM stage, and tumor location. Moreover, based on the propensity score, an IPTW analysis was conducted. Patients who received firstline FLOT were weighted by 1 /propensity score, whereas patients who underwent first-line surgery were weighted by $1 /(1-$ propensity score $)$.

In both models, Kaplan-Meier curves with the log-rank tests were used to calculate the overall cumulative probability. Univariate and multivariate Cox models were performed to compare the groups in the PSM analysis. A $P$-value $<0.05$ was considered statistically significant. Statistical analyses were conducted using Statistical Product for Social Sciences (SPSS) software (version 23.0; Inc, Chicago, IL, USA) and Empower-Stats (http:// www.empowerststs.com, X\&Y Solutions, Inc, Boston, MA, USA).

\section{Results}

\section{Patients' characteristics}

From 2013 to 2017, a total of 316 LAGC patients were included in this study, of whom 47 patients received preoperative FLOT regimen chemotherapy and 269 patients received initial surgery after diagnosis. The baseline data of the patients are shown in Table 1. As shown in Table 1, there was a significant difference between the two groups in the clinical TNM stage and the time of diagnosis. The propensity score obtained by multivariate logistic regression analysis showed an AUC of 0.75 and a $P$-value of the Hosmer-Lemeshow test of 0.414, which suggested a reasonable data model.

\section{Survival analysis}

The median follow-up time for the entire study was 41 months (12-67 months). In the unmatched study, the median survival time for patients in the initial FLOT group and that in the initial surgery group was 44 months and 23 months $(P=0.01)$, respectively. The 3-year survival rates in the initial FLOT group and that in the initial surgery group were $60.1 \%$ and $36.5 \%$, respectively; the 5-year survival rates were $43.8 \%$ and $26.8 \%$, respectively (Figure 1A, Table 2). The 
Table I Demographic and clinical characteristics before and after PSM analysis

\begin{tabular}{|c|c|c|c|c|c|c|}
\hline \multirow[t]{3}{*}{ Variables } & \multicolumn{2}{|c|}{ Before PSM $(n=3 \mid 6)$} & \multirow[t]{3}{*}{ P-value } & \multicolumn{2}{|c|}{ After PSM (n=82) } & \multirow[t]{3}{*}{$P$-value } \\
\hline & $\begin{array}{l}\text { Surgery-first } \\
n=269\end{array}$ & $\begin{array}{l}\text { FLOT-first } \\
n=47\end{array}$ & & $\begin{array}{l}\text { Surgery-first } \\
n=41\end{array}$ & $\begin{array}{l}\text { FLOT-first } \\
n=41\end{array}$ & \\
\hline & n (\%) & n (\%) & & n (\%) & n (\%) & \\
\hline $\begin{array}{l}\text { Age (years) } \\
\quad<60 \\
\quad \geq 60\end{array}$ & $\begin{array}{l}152(56.5) \\
117(43.5)\end{array}$ & $\begin{array}{l}27(57.4) \\
20(42.6)\end{array}$ & 0.9 & $\begin{array}{l}24(58.5) \\
17(4 I .5)\end{array}$ & $\begin{array}{l}23(56.1) \\
18(43.9)\end{array}$ & I \\
\hline $\begin{array}{l}\text { Gender } \\
\text { Male } \\
\text { Female }\end{array}$ & $\begin{array}{l}196(72.9) \\
73(27.1)\end{array}$ & $\begin{array}{l}38(80.9) \\
9(19.1)\end{array}$ & 0.28 & $\begin{array}{l}32(78) \\
9(22)\end{array}$ & $\begin{array}{l}33(80.5) \\
8(19.5)\end{array}$ & I \\
\hline $\begin{array}{l}\text { Lauren classification } \\
\text { Intestinal } \\
\text { Diffuse } \\
\text { Mixed }\end{array}$ & $\begin{array}{l}118(43.9) \\
85(31.6) \\
66(24.5)\end{array}$ & $\begin{array}{l}20(42.6) \\
17(36.2) \\
10(21.3)\end{array}$ & 0.8 & $\begin{array}{l}18(43.9) \\
10(24.4) \\
13(31.7)\end{array}$ & $\begin{array}{l}15(36.6) \\
16(39) \\
10(24.4)\end{array}$ & 0.36 \\
\hline $\begin{array}{l}\text { Tumor location } \\
\text { Upper third } \\
\text { Middle third } \\
\text { Lower third }\end{array}$ & $\begin{array}{l}65(24.4) \\
116(43.6) \\
85(32.0)\end{array}$ & $\begin{array}{l}13(27.7) \\
24(51.1) \\
10(21.3)\end{array}$ & 0.34 & $\begin{array}{l}12(29.3) \\
19(46.3) \\
10(24.4)\end{array}$ & $\begin{array}{l}10(24.4) \\
21(51.2) \\
10(24.4)\end{array}$ & 0.87 \\
\hline $\begin{array}{l}\text { Clinical TNM stage } \\
\text { II } \\
\text { III }\end{array}$ & $\begin{array}{l}119(44.2) \\
150(55.8)\end{array}$ & $\begin{array}{l}\text { II (23.4) } \\
36(76.6)\end{array}$ & 0.01 & $\begin{array}{l}\text { II (26.8) } \\
30(73.2)\end{array}$ & $\begin{array}{l}\text { II (26.8) } \\
30(73.2)\end{array}$ & I \\
\hline $\begin{array}{l}\text { Diagnose time } \\
2013 \sim 2014 \\
2015 \sim 2016 \\
2017\end{array}$ & $\begin{array}{l}100(37.2) \\
132(49.1) \\
37(13.8)\end{array}$ & $\begin{array}{l}7(14.9) \\
17(36.2) \\
23(48.9)\end{array}$ & 0.001 & $\begin{array}{l}7(17.1) \\
17(4 \mid .5) \\
17(4 I .5)\end{array}$ & $\begin{array}{l}7(17.1) \\
17(41.5) \\
17(41.5)\end{array}$ & I \\
\hline
\end{tabular}

Abbreviations: PSM, propensity matched; FLOT, docetaxel, oxaliplatin, leucovorin, and 5-fluorouracil.

results of the multivariate analyses showed that treatment approach and clinical TNM stage were independent factors affecting patients' survival. In addition, the adjusted HR of FLOT-first compared with surgery-first for OS was 0.417 (95\% CI, $0.23-0.755, P=0.004$ ) (Table S1). In the head-to head PSM analysis, 41 patients treated with FLOT-first and 41 patients treated with surgery-first were successfully matched, and the age, sex, tumor location, Lauren classification, clinical TNM stage, and time of diagnose were balanced between the two groups (Table 1). The results of the multivariate analysis indicated that initial FLOT was associated with a significant $\mathrm{OS}$ benefit compared with initial surgery (HR, 0.416; 95\% CI, 0.218-0.794; $P=0.008$ ) (Table 3). The median survival time for patients in the FLOT-first group and that in the surgery-first group was 44 months and 15 months $(P=0.008)$, respectively. The 3 -year survival rate in the FLOT-first group and surgery-first group was $58.7 \%$ and $30.9 \%$, respectively (Figure 1B, Table 2). The IPTW analysis showed a similar result; The 3-year survival rate in the
FLOT-first group and the surgery-first group was $68.6 \%$ and $35.4 \%(P<0.001)$, respectively (Figure $1 \mathrm{C}$, Table 2$)$. In the exploratory subgroup analysis of the matched cohort, there were no significantly different effects of FLOT on OS across all subgroups examined (Figure 2). However, in stage II subgroup, patients who received FLOT-first treatment did not show a beneficial survival (HR, 0.868; 95\% CI, 0.215-3.504).

\section{Response and toxicity analysis}

In this study, only $1(2.1 \%)$ patient achieved CR, 15 (42.6\%) patients achieved PR, 17 (44.7\%) patients were in $\mathrm{SD}$, and $3(6.4 \%)$ patients were in progressive disease (PD) according to CT contrast before and after chemotherapy. Two patients' data were lost. After surgery, $1(2.1 \%)$ patient was not found to have cancer tissue (PCR), and the R0 resection rate was $91 \%$ in the FLOT-first cohort (Table 4). In the FLOT-first cohort, the results of multivariate analysis showed that the 

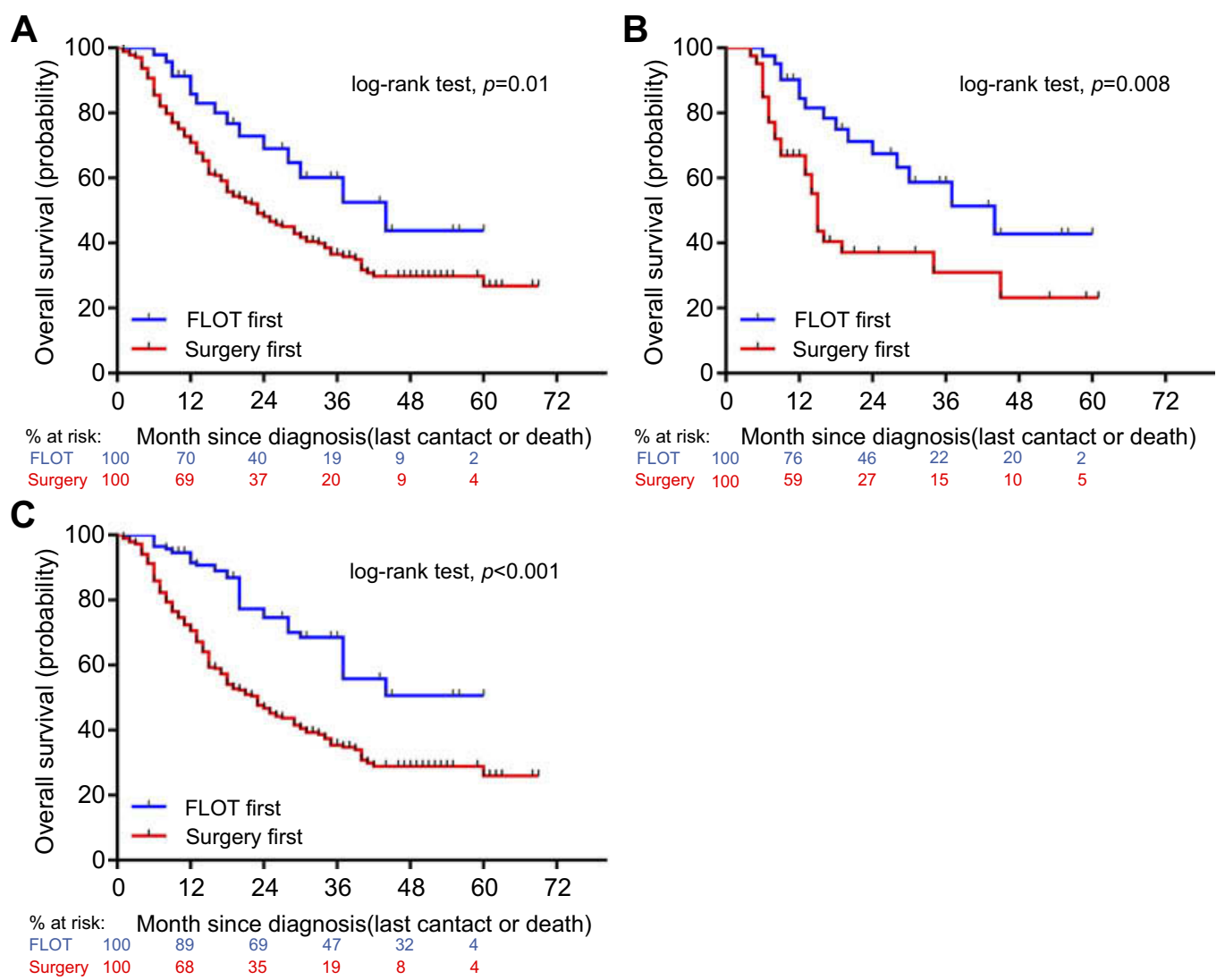

Figure I Overall survival in (A) the unmatched, (B) the propensity score-matched analysis, (C) the inverse probability of treatment weight-adjusted analysis according to the different initial treatments in patients with clinical T3-4 locally advanced gastric cancer.

Abbreviation: FLOT, docetaxel, oxaliplatin, leucovorin, and 5-fluorouracil.

Table 2 Overall survival for FLOT-first versus surgery-first in patients with locally advanced gastric cancer

\begin{tabular}{|c|c|c|c|c|c|c|}
\hline \multirow[t]{2}{*}{ Year } & \multicolumn{2}{|c|}{ Unmatched (\%) } & \multicolumn{2}{|c|}{ PSM (\%) } & \multicolumn{2}{|c|}{ IPTW (\%) } \\
\hline & FLOT & Surgery & FLOT & Surgery & FLOT & Surgery \\
\hline I & 85.8 & 70.8 & 84.4 & 66.8 & 91.5 & 70.5 \\
\hline 2 & 69.0 & 48.1 & 67.5 & 37.1 & 74.6 & 46.7 \\
\hline 3 & 60.1 & 36.5 & 58.7 & 30.9 & 68.6 & 35.4 \\
\hline 4 & 43.8 & 29.8 & 42.8 & 23.2 & 50.6 & 28.9 \\
\hline 5 & 43.8 & 26.8 & - & - & - & 26.0 \\
\hline
\end{tabular}

Abbreviations: FLOT, docetaxel, oxaliplatin, leucovorin, and 5-fluorouracil; PSM, propensity score - matched; IPTW, inverse probability of treatment weighting.

response to chemotherapy (HR, 8.21; $95 \% \mathrm{CI}$, $1.66-40.56, P=0.005)$ and gender (HR, 6.322; 95\% CI, $1.75-22.91 ; P=0.01)$ were independent factors associated with survival (Table S2). Throughout the course of chemotherapy, the main grade 3-4 toxicities were mainly leukopenia (36\%), dizziness $(9 \%)$, nausea $(25 \%)$, and vomiting $(3 \%)$. No patient dropped out due to severe toxic reactions. In addition, G-CSF was administered in 23 patients and no treatment-related death occurred.

\section{Postoperative pathology results}

The extent of resection, surgical complications, pT stage of tumor invasion, and $\mathrm{pN}$ stage of lymph node according to the 7th edition AJCC guidelines are summarized in Table 5. ${ }^{14}$ We can conclude that in the unmatched study, the R0 resection rate was $88.4 \%$ in the FLOT group and $86.4 \%$ in the surgery group. In the PSM analysis, the R0 resection rate was $89.2 \%$ in the FLOT group and $84.6 \%$ in the surgery group (all $P>0.05$ ). After surgery, there was significant difference only in the $\mathrm{pN}$ stage between the two groups 
Table 3 Univariate and multivariate analysis of survival in PSM analysis $(n=82)$

\begin{tabular}{|c|c|c|c|c|c|c|}
\hline \multirow[t]{2}{*}{ Variables } & \multicolumn{2}{|c|}{ Univariate analysis } & \multirow[t]{2}{*}{$P$-value } & \multicolumn{2}{|c|}{ Multivariate analysis } & \multirow[t]{2}{*}{$P$-value } \\
\hline & HR & $95 \% \mathrm{Cl}$ & & HR & $95 \% \mathrm{Cl}$ & \\
\hline $\begin{array}{l}\text { Treatment } \\
\text { FLOT-first } \\
\text { Surgery-first }\end{array}$ & $\begin{array}{l}0.434 \\
1\end{array}$ & $0.228 \sim 0.826$ & 0.011 & $\begin{array}{l}0.416 \\
1\end{array}$ & $0.218 \sim 0.794$ & 0.008 \\
\hline $\begin{array}{l}\text { Age (years) } \\
\quad<60 \\
\geq 60\end{array}$ & $\begin{array}{l}1 \\
1.699\end{array}$ & $0.899 \sim 3.209$ & 0.103 & & & \\
\hline $\begin{array}{l}\text { Gender } \\
\text { Male } \\
\text { Female }\end{array}$ & 1 & $0.824 \sim 3.205$ & 0.161 & & & \\
\hline $\begin{array}{l}\text { Lauren classification } \\
\text { Intestinal } \\
\text { Diffuse } \\
\text { Mixed }\end{array}$ & $\begin{array}{l}1 \\
1.386 \\
1.332\end{array}$ & $\begin{array}{l}0.651 \sim 2.953 \\
0.620 \sim 2.859\end{array}$ & 0.648 & & & \\
\hline $\begin{array}{l}\text { Tumor location } \\
\text { Upper third } \\
\text { Middle third } \\
\text { Lower third }\end{array}$ & $\begin{array}{l}1 \\
1.147 \\
1.481\end{array}$ & $\begin{array}{l}0.485 \sim 2.709 \\
0.578 \sim 3.79\end{array}$ & 0.674 & & & \\
\hline $\begin{array}{l}\text { Clinical TNM stage } \\
\text { II } \\
\text { III }\end{array}$ & $\begin{array}{l}1 \\
2.24 I\end{array}$ & $1.021-4.916$ & 0.044 & $\begin{array}{l}\text { I } \\
2.378\end{array}$ & $1.076 \sim 5.265$ & 0.032 \\
\hline $\begin{array}{l}\text { Diagnose time } \\
2013 \sim 2014 \\
2015 \sim 2016 \\
2017\end{array}$ & $\begin{array}{l}1 \\
0.476 \\
0.641\end{array}$ & $\begin{array}{l}0.175 \sim 1.29 \\
0.303 \sim 1.356\end{array}$ & 0.305 & & & \\
\hline $\begin{array}{l}\text { Postoperative chemotherapy } \\
\text { FLOT } \\
\text { FOLFOX6 } \\
\text { XELOX } \\
\text { SOX }\end{array}$ & $\begin{array}{l}1 \\
1.194 \\
2.769 \\
2.324\end{array}$ & $\begin{array}{l}0.36 \sim 3.964 \\
0.369 \sim 20.76 \\
1.13 \sim 4.778\end{array}$ & 0.122 & & & \\
\hline $\begin{array}{l}\text { Style of operation } \\
\text { Total gastrectomy } \\
\text { Subtotal gastrectomy } \\
\text { Distal gastrectomy }\end{array}$ & $\begin{array}{l}1 \\
1.292 \\
0.435\end{array}$ & $\begin{array}{l}0.66 \sim 2.53 \\
0.158 \sim 1.201\end{array}$ & 0.095 & & & \\
\hline
\end{tabular}

Notes: Adjusted HR (95\%) was adjusted by age, gender, Lauren classification, tumor location, clinical TNM stage, diagnose time, postoperative chemotherapy, and style of operation. Variables that had no significant differences in univariate analysis were not included in the multivariate analysis.

Abbreviations: PSM, propensity matched; FLOT, docetaxel, oxaliplatin, leucovorin, and 5-fluorouracil; FOLFOX6, oxaliplatin, leucovorin and 5-fluorouracil.

after PSM $(P=0.006)$, and percentage of patients without lymph node metastasis was slightly high in the FLOT-first cohort.

\section{Discussion}

The positive impact of neoadjuvant chemotherapy on survival in patients with locally advanced gastric adenocarcinoma has become clearer over time, although there is no consensus as to the best approach. The best chemotherapy regimen for neoadjuvant therapy is not established, and practice is variable. Although the FLOT regimen demonstrated higher 5-year survival and disease-free survival rates in the treatment of GC and gastroesophageal junction cancer than the previous regimen, ${ }^{11}$ whether this regimen can achieve similar results in GC patients in China has not been reported. 


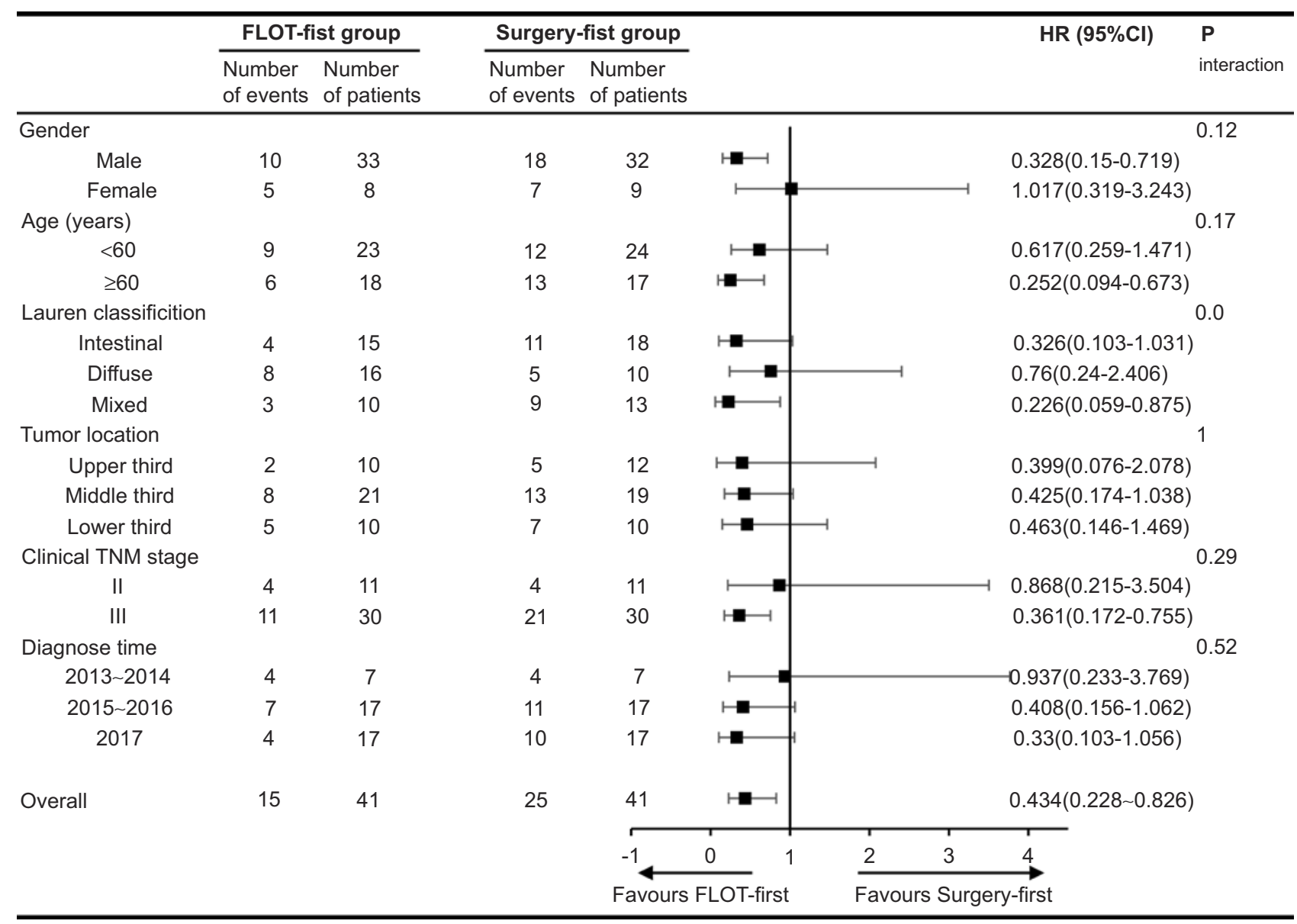

Figure 2 Subgroup analysis in the propensity score-matched analysis.

Abbreviation: FLOT, docetaxel, oxaliplatin, leucovorin, and 5-fluorouracil.

Table 4 Tumor response according to RECIST I.I criteria

\begin{tabular}{|l|l|l|l|}
\hline Tumor response & Number of patients & $\%$ & $\mathbf{9 5 \%} \mathbf{~ C l}$ \\
\hline CR & 1 & 2.1 & \\
PR & 20 & 42.6 & \\
CR+PR & 21 & 44.7 & $30.5-58.9$ \\
SD & 21 & 44.7 & \\
PD & 3 & 6.4 & \\
NE & 2 & 4.2 & \\
\hline
\end{tabular}

Abbreviations: $\mathrm{CR}$, complete response; $\mathrm{PR}$, partial response; $\mathrm{SD}$, stable disease; $\mathrm{PD}$, progression of disease; $\mathrm{NE}$, not evaluable.

Our head-to-head study based on the propensity score, for the first time, directly compared the survival benefit of preoperative FLOT chemotherapy with initial surgery followed by adjuvant chemotherapy. We found that patients who received neoadjuvant chemotherapy with the FLOT regimen had a lower mortality rate and a median survival time of approximately 10 more months compared with patients who underwent initial surgery. This benefit profile is consistent with that obtained in the IPTW study, and the consistency of the results from these two analyses can further support our conclusions.

For patients with potentially resectable AGC, randomized trials and meta-analyses indicate a significant survival benefit over surgery alone for the number of approaches, including neoadjuvant chemotherapy. At least four trials have directly compared surgery alone with neoadjuvant or perioperative chemotherapy, three of which demonstrated a survival benefit for this approach. In the Phase III MAGIC trial, ${ }^{9}$ the HR of the ECF regimen compared with surgery for OS was $0.75(95 \%$ CI, 0.60-0.93). In the large multicenter randomized controlled trial 07-FFCD 9703 in France, ${ }^{10}$ the HR was 0.69 (95\% CI, $0.50-0.95)$ in the DCF regimen compared with the surgery alone. Fiteni et $\mathrm{al}^{15}$ conducted a large retrospective study based on the propensity score. In Fiteni's study, the DCF regimen was compared with the surgery group, and the 5-year survival rate was $0.293(95 \% \mathrm{CI}, 0.135-0.636)$ in the treatment of gastroesophageal junction cancer. In these three studies, R0 resection rates were $69 \%, 84 \%$, and 
Table 5 Postoperative pathology report

\begin{tabular}{|c|c|c|c|c|c|c|}
\hline \multirow[t]{3}{*}{ Variables } & \multicolumn{2}{|c|}{ Before PSM } & \multirow[t]{3}{*}{$P$-value } & \multicolumn{2}{|l|}{ After PSM } & \multirow[t]{3}{*}{$P$-value } \\
\hline & $\begin{array}{l}\text { FLOT-first } \\
n=47\end{array}$ & $\begin{array}{l}\text { Surgery-first } \\
N=269\end{array}$ & & $\begin{array}{l}\text { FLOT-first } \\
n=41\end{array}$ & $\begin{array}{l}\text { Surgery-first } \\
N=4 I\end{array}$ & \\
\hline & n (\%) & n (\%) & & n (\%) & n (\%) & \\
\hline $\begin{array}{l}\text { R0 resection } \\
\text { Yes } \\
\text { No } \\
\text { Missing }\end{array}$ & $\begin{array}{l}38(88.4) \\
5(11.6) \\
4\end{array}$ & $\begin{array}{l}223(86.4) \\
35(13.6) \\
11\end{array}$ & 0.729 & $\begin{array}{l}33(89.2) \\
4(10.8) \\
4\end{array}$ & $\begin{array}{l}33(84.6) \\
6(15.4) \\
2\end{array}$ & 0.737 \\
\hline $\begin{array}{l}\text { PT } \\
\text { T0 } \\
\text { T2 } \\
\text { T3 } \\
\text { T4 } \\
\text { Missing }\end{array}$ & $\begin{array}{l}\text { I }(2.3) \\
\text { I }(2.3) \\
\text { I3 (30.2) } \\
28(65.1) \\
4\end{array}$ & $\begin{array}{l}- \\
7(2.7) \\
68(26.4) \\
183(70.9) \\
11\end{array}$ & 0.094 & $\begin{array}{l}\text { I }(2.7) \\
\text { I }(2.7) \\
\text { I2 (32.4) } \\
23(62.2) \\
4\end{array}$ & $\begin{array}{l}0 \\
2(5.1) \\
8(20.5) \\
29(74.4) \\
2\end{array}$ & 0.491 \\
\hline $\begin{array}{l}\text { PN } \\
\text { No } \\
\text { NI } \\
\text { N2 } \\
\text { N3 } \\
\text { Missing }\end{array}$ & $\begin{array}{l}17(39.5) \\
10(23.3) \\
7(16.3) \\
9(20.9) \\
4\end{array}$ & $\begin{array}{l}66(25.6) \\
48(18.6) \\
50(19.4) \\
94(36.4) \\
11\end{array}$ & 0.122 & $\begin{array}{l}15(40.5) \\
7(18.9) \\
7(18.9) \\
8(21.6) \\
4\end{array}$ & $\begin{array}{l}3(7.7) \\
7(18.9) \\
12(30.8) \\
17(43.6) \\
2\end{array}$ & 0.006 \\
\hline $\begin{array}{l}\text { Major surgical complications }{ }^{\mathrm{a}} \\
\text { Yes } \\
\text { No } \\
\text { Missing }\end{array}$ & $\begin{array}{l}8(17) \\
39(83) \\
-\end{array}$ & $\begin{array}{l}41(16) \\
215(84) \\
13\end{array}$ & 0.831 & $\begin{array}{l}4(9.8) \\
37(90.2) \\
-\end{array}$ & $\begin{array}{l}7(17.1) \\
34(82.9) \\
-\end{array}$ & 0.519 \\
\hline
\end{tabular}

Note: a Grade 3-5 Clavien-Dindo classification.

Abbreviations: FLOT, docetaxel, oxaliplatin, leucovorin, and 5-fluorouracil; PSM, propensity matched; pT, pathological tumor invasion; pN, pathological lymph node metastasis; $\mathrm{N}$, number.

$90.32 \%$. These results illustrate the potential superiority of docetaxel in the neoadjuvant chemotherapy regimen. In our study, the adjusted HR was 0.417 (95\% CI, 0.23-0.755) for the FLOT-first compared with surgery-first, and the 3-year survival rate was $60.1 \%$. The 3 -year survival rate was similar to the $57 \%$ result in the stage III FLOT-AIO4 trial and $60 \%$ in the Fiteni study and is superior to the $45 \%$ in the MAGIC trial and 50\% in FFCD trial. ${ }^{9,10,16}$ Although the biological behavior of gastroesophageal junction cancer and distal GC included in these studies are different, the results may indicate the potential advantages of FLOT as a neoadjuvant chemotherapy regimen. In addition, the R0 resection rate in our study was $88.4 \%$, which is similar to the result of $86 \%$ reported in a Phase II clinical study (NeoFLOT) in Germany, where the patients included were (consistent with our study) all in cT3-4 stage. ${ }^{17}$ Furthermore, there was a significant difference in postoperative lymph node $\mathrm{N}$ stage between the two groups in the PSM analysis, and the number of patients without lymph node metastasis was slightly high in the FLOT-first cohort, which may mean that the number of lymph node metastases can be reduced by the FLOT regimen to achieve the goal of downstage treatment. A meta-analysis conducted by Coccolini $\mathrm{F}$ also reached a similar conclusion. ${ }^{13}$ In addition, in the further subgroup analysis, we found that for stage II patients, preoperative FLOT chemotherapy did not show a better benefit (HR, 0.868, 95\% CI, 0.215-3.504). This indicated that the FLOT regimen might not be effective in patients without lymph node metastasis, because only cT3-4 patients were included in our study, and those with stage II had no lymph node metastasis.

Previous findings have confirmed that response to chemotherapy is closely related to the prognosis of patients with GC and gastroesophageal junction cancer, ${ }^{18,19}$ and this conclusion is also consistent with the results of our research. In the Neo-FLOT study, ${ }^{17}$ PCR in the FLOT regimen reached $20 \%$ and RR reached $40 \%$. In the FLOT4 trial, PCR reached $15 \%$ and $16 \%$ in gastric and gastroesophageal junction cancers, respectively. ${ }^{11}$ In addition, PCR was 5\% in the study by Simon, and the response 
rate was even higher at $66 \%{ }^{20}$ Although only 1 patient in our study achieved PCR (7\%), which is lower than the above study, the overall response rate reached $44.7 \%$ and is better than the overall response rate of $37 \%$ in the V325 study, ${ }^{21}$ which also included a docetaxel-containing DCF regimen. Although limited by the fact that this comparison was made between different trials, we cannot directly conclude that the FLOT regimen is superior to other docetaxel-containing chemotherapy regimens; however, this result still demonstrates the potential superiority of FLOT over DCF and other docetaxel-containing chemotherapy regimens in terms of chemotherapy effectiveness.

There is no doubt that chemotherapy regimens including docetaxel increase the risk of hematologic toxicities and nonhematologic side effects. In the FLOT4 trial, ${ }^{11}$ chemotherapy-related grade 3-4 adverse effects were mainly leukopenia $(36 \%)$, dizziness $(9 \%)$, and vomiting $(3 \%)$. In our study, to ensure safety and avoid unnecessary drug reductions during FLOT administration, we used prophylactic antiemetics in each patient. Additionally, granulocytecolony stimulating factor (G-CSF) was used for patients with fewer than $4 \times 10^{9}$ leukocytes. Leukopenia and vomiting remained the most predominant side effects of chemotherapy with results similar to those observed in the FLOT4 trial, but these were clinically acceptable grade 3-4 toxicities. $^{22}$ In the present study, no patient dropped out due to unbearable or severe side effects and no treatment-related deaths occurred.

Our study has some limitations and deficiencies. First, there were only 47 patients in the FLOT-first group, and the effect of FLOT for patients without lymph node metastasis still needs to be verified by a larger sample; second, as a retrospective study, although the statistical method based on the propensity score can effectively eliminate observed confounders, it cannot control for unobserved confounders; thus, it is impossible to reach the level of evidence of randomized controlled studies. However, the efficacy of the FLOT regimen for patients with $\mathrm{LAGC}$ within the tolerable toxicity levels is consistent with the results of previous studies. Furthermore, tumor staging and efficacy evaluation were all conducted through CT, gastroscopy, or MRI. Similar to many previous studies, these traditional methods can only evaluate tumors and tumor changes from a morphological point of view. It is difficult to achieve an accurate evaluation, and a high degree of consistency cannot be maintained with pathological findings, which may affect the matching and comparison of the two groups of patients.

\section{Conclusion}

Our study demonstrated that preoperative FLOT regimen chemotherapy was superior to initial surgery for patients with LAGC in terms of OS. We suggest that the use of the FLOT regimen as neoadjuvant chemotherapy should be taken into consideration during the comprehensive treatment of patients with LAGC. Rigorous randomized studies are needed to determine the role of FLOT and optimal patient selection in the Chinese population.

\section{Ethical statement}

To preserve patient privacy and data confidentiality, patient data have been identified before analysis. All analyses in this retrospective study were performed based on the data from anonymized patients. Due to the retrospective nature of this study, the Ethics Committee of Lanzhou University Second Hospital approved the study and determined that written informed consent was not required.

\section{Acknowledgment}

This study was funded by the National Natural Science Foundation of China (Grant No.31670847) and Gansu Provincial Key Research and Development Program (No.17YF1FA127). Dr Keshen Wang and Yanxian Ren are co-first authors.

\section{Disclosure}

The authors report no conflicts of interest in this study.

\section{References}

1. Bray F, Ferlay J, Soerjomataram I, Siegel RL, Torre LA, Jemal A. Global cancer statistics 2018: GLOBOCAN estimates of incidence and mortality worldwide for 36 cancers in 185 countries. CA Cancer J Clin. 2018;68(6):394-424. doi:10.3322/caac.21492

2. Patru CL, Surlin V, Georgescu I, Patru E. Current issues in gastric cancer epidemiology. Rev Med Chir Soc Med Nat Iasi. 2013;117 (1):199-204.

3. Ajani JA, Ota DM, Jessup JM, et al. Resectable gastric carcinoma. An evaluation of preoperative and postoperative chemotherapy. Cancer. 1991;68(7):1501-1506.

4. Ajani JA, Mansfield PF, Ota DM. Potentially resectable gastric carcinoma: current approaches to staging and preoperative therapy. World J Surg. 1995;19(2):216-220.

5. Ajani JA, Mayer RJ, Ota DM, et al. Preoperative and postoperative combination chemotherapy for potentially resectable gastric carcinoma. J Natl Cancer Inst. 1993;85(22):1839-1844.

6. Leichman L, Silberman H, Leichman CG, et al. Preoperative systemic chemotherapy followed by adjuvant postoperative intraperitoneal therapy for gastric cancer: a University of Southern California pilot program. J Clin Oncol. 1992;10(12):1933-1942. doi:10.1200/JCO.1992.10.12.1933 
7. Yoshikawa T, Sasako M, Yamamoto S, et al. Phase II study of neoadjuvant chemotherapy and extended surgery for locally advanced gastric cancer. Br J Surg. 2009;96(9):1015-1022. doi:10.1002/bjs.6665

8. Persiani R, Rausei S, Pozzo C, et al. 7-Year survival results of perioperative chemotherapy with epidoxorubicin, etoposide, and cisplatin (EEP) in locally advanced resectable gastric cancer: up-to-date analysis of a phase-II study. Ann Surg Oncol. 2008;15(8):2146-2152. doi:10.1245/s10434-008-9982-2

9. Cunningham D, Allum WH, Stenning SP, et al. Perioperative chemotherapy versus surgery alone for resectable gastroesophageal cancer. N Engl J Med. 2006;355(1):11-20. doi:10.1056/NEJMoa055531

10. Ychou M, Boige V, Pignon JP, et al. Perioperative chemotherapy compared with surgery alone for resectable gastroesophageal adenocarcinoma: an FNCLCC and FFCD multicenter phase III trial. $J$ Clin Oncol. 2011;29(13):1715-1721. doi:10.1200/JCO.2010.33.0597

11. Al-Batran SE, Hofheinz RD, Pauligk C, et al. Histopathological regression after neoadjuvant docetaxel, oxaliplatin, fluorouracil, and leucovorin versus epirubicin, cisplatin, and fluorouracil or capecitabine in patients with resectable gastric or gastro-oesophageal junction adenocarcinoma (FLOT4-AIO): results from the phase 2 part of a multicentre, open-label, randomised phase 2/3 trial. Lancet Oncol. 2016;17(12):1697-1708. doi:10.1016/S1470-2045(16)30531-9

12. Xu AM, Huang L, Liu W, Gao S, Han WX, Wei ZJ. Neoadjuvant chemotherapy followed by surgery versus surgery alone for gastric carcinoma: systematic review and meta-analysis of randomized controlled trials. PLoS One. 2014;9(1):e86941. doi:10.1371/journal.pone.0086941

13. Coccolini F, Nardi M, Montori G, et al. Neoadjuvant chemotherapy in advanced gastric and esophago-gastric cancer. Meta-analysis of randomized trials. Int J Surg. 2018;51:120-127. doi:10.1016/j.ijsu.2018.01.008

14. Edge SB, Compton CC. The American Joint Committee on Cancer: the 7th edition of the AJCC cancer staging manual and the future of TNM. Ann Surg Oncol. 2010;17(6):1471-1474. doi:10.1245/s10434-010-0985-4

15. Fiteni F, Paget-Bailly S, Messager M, et al. Docetaxel, cisplatin, and 5-fluorouracil as perioperative chemotherapy compared with surgery alone for resectable gastroesophageal adenocarcinoma. Cancer Med. 2016;5(11):3085-3093. doi:10.1002/cam4.885
16. Al-Batran SE, Pauligk C, Homann N, et al. LBA-008Docetaxel, oxaliplatin, and fluorouracil/leucovorin (FLOT) versus epirubicin, cisplatin, and fluorouracil or capecitabine $(\mathrm{ECF} / \mathrm{ECX})$ as perioperative treatment of resectable gastric or gastro-esophageal junction adenocarcinoma: the multicenter, randomized phase 3 FLOT4 trial (German Gastric Group at AIO). Ann Oncol. 2017;28(suppl_3). doi:10.1093/annonc/mdx075.

17. Schulz C, Kullmann F, Kunzmann V, et al. NeoFLOT: multicenter phase II study of perioperative chemotherapy in resectable adenocarcinoma of the gastroesophageal junction or gastric adenocarcinoma-very good response predominantly in patients with intestinal type tumors. Int J Cancer. 2015;137(3):678-685. doi:10.1002/ijc.29403

18. Fields RC, Strong VE, Gonen M, et al. Recurrence and survival after pathologic complete response to preoperative therapy followed by surgery for gastric or gastrooesophageal adenocarcinoma. $\mathrm{Br}$ J Cancer. 2011;104(12):1840-1847. doi:10.1038/bjc.2011.175

19. Becker K, Langer R, Reim D, et al. Significance of histopathological tumor regression after neoadjuvant chemotherapy in gastric adenocarcinomas: a summary of 480 cases. Ann Surg. 2011;253 (5):934-939. doi:10.1097/SLA.0b013e318216f449

20. Pernot S, Mitry E, Samalin E, et al. Biweekly docetaxel, fluorouracil, leucovorin, oxaliplatin (TEF) as first-line treatment for advanced gastric cancer and adenocarcinoma of the gastroesophageal junction: safety and efficacy in a multicenter cohort. Gastric Cancer. 2014;17 (2):341-347. doi:10.1007/s10120-013-0266-6

21. Van Cutsem E, Moiseyenko VM, Tjulandin S, et al. Phase III study of docetaxel and cisplatin plus fluorouracil compared with cisplatin and fluorouracil as first-line therapy for advanced gastric cancer: a report of the V325 Study Group. J Clin Oncol. 2006;24(31):4991-4997. doi:10.1200/JCO.2006.06.8429

22. Al-Batran SE, Hartmann JT, Hofheinz R, et al. Biweekly fluorouracil, leucovorin, oxaliplatin, and docetaxel (FLOT) for patients with metastatic adenocarcinoma of the stomach or esophagogastric junction: a phase II trial of the Arbeitsgemeinschaft Internistische Onkologie. Ann Oncol. 2008;19(11):1882-1887. doi:10.1093/ annonc/mdn403 


\section{Supplementary materials}

Table SI Univariate and multivariate analysis of survival before PSM analysis $(n=3 \mid 3)$

\begin{tabular}{|c|c|c|c|c|c|c|}
\hline \multirow[t]{2}{*}{ Variables } & \multicolumn{2}{|c|}{ Univariate analysis } & \multirow[t]{2}{*}{$P$-value } & \multicolumn{2}{|c|}{ Multivariate analysis } & \multirow[t]{2}{*}{$P$-value } \\
\hline & HR & $95 \% \mathrm{Cl}$ & & HR & $95 \% \mathrm{Cl}$ & \\
\hline $\begin{array}{l}\text { Treatment } \\
\text { FLOT-first } \\
\text { Surgery-first }\end{array}$ & $\begin{array}{l}0.522 \\
1\end{array}$ & $0.307 \sim 0.886$ & 0.016 & $\begin{array}{l}0.417 \\
1\end{array}$ & $0.23 \sim 0.755$ & 0.004 \\
\hline $\begin{array}{l}\text { Age } \\
\qquad 60 \\
\geq 60\end{array}$ & $\begin{array}{l}1 \\
1.039\end{array}$ & $0.768 \sim 1.406$ & 0.802 & & & \\
\hline $\begin{array}{l}\text { Gender } \\
\text { Male } \\
\text { Female }\end{array}$ & 1 & $0.726 \sim 1.422$ & 0.928 & & & \\
\hline $\begin{array}{l}\text { Lauren classification } \\
\text { Intestinal } \\
\text { Diffuse } \\
\text { Mixed }\end{array}$ & $\begin{array}{l}1 \\
1.619 \\
1.187\end{array}$ & $\begin{array}{l}0.147 \sim 2.286 \\
0.801 ! 1.759\end{array}$ & 0.022 & $\begin{array}{l}1 \\
1.412 \\
1.022\end{array}$ & $\begin{array}{l} \\
0.997 \sim 1.999 \\
0.685 \sim 1.524\end{array}$ & 0.109 \\
\hline $\begin{array}{l}\text { Tumor location } \\
\text { Upper third } \\
\text { Middle third } \\
\text { Lower third }\end{array}$ & $\begin{array}{l}\mathrm{I} \\
1.046 \\
\mathrm{I} .277\end{array}$ & $\begin{array}{l}0.703 \sim 1.557 \\
0.843 \sim 1.933\end{array}$ & 0.426 & & & \\
\hline $\begin{array}{l}\text { Clinical TNM stage } \\
\text { II } \\
\text { III }\end{array}$ & $\begin{array}{l}1 \\
2.878\end{array}$ & $2.047 \sim 4.044$ & $<0.001$ & $\begin{array}{l}1 \\
3.122\end{array}$ & $2.197 \sim 4.438$ & $<0.001$ \\
\hline $\begin{array}{l}\text { Diagnose time } \\
2013 \sim 2014 \\
2015 \sim 2016 \\
2017\end{array}$ & $\begin{array}{l}1 \\
0.848 \\
0.698\end{array}$ & $\begin{array}{l}0.615 \sim 1.170 \\
0.393 \sim 1.240\end{array}$ & 0.357 & & & \\
\hline $\begin{array}{l}\text { Postoperative chemotherapy } \\
\text { FLOT } \\
\text { FOLFOX6 } \\
\text { XELOX } \\
\text { SOX }\end{array}$ & $\begin{array}{l}1 \\
1.235 \\
1.662 \\
1.614\end{array}$ & $\begin{array}{l} \\
0.83 \sim 1.838 \\
1.082 \sim 2.554 \\
1.072 \sim 2.429\end{array}$ & 0.049 & $\begin{array}{l}1 \\
0.904 \\
0.751 \\
1.235\end{array}$ & $\begin{array}{l}0.581 \sim 1.405 \\
0.48 \sim 1.178 \\
0.766 \sim 1.99\end{array}$ & 0.21 \\
\hline $\begin{array}{l}\text { Style of operation } \\
\text { Total gastrectomy } \\
\text { Subtotal gastrectomy } \\
\text { Distal gastrectomy }\end{array}$ & $\begin{array}{l}1 \\
1.241 \\
0.714\end{array}$ & $\begin{array}{l}0.898 \sim 1.715 \\
0.437 \sim 1.168\end{array}$ & 0.062 & & & \\
\hline
\end{tabular}

Notes: Adjusted HR (95\%) was adjusted by age, gender, Lauren classification, tumor location, clinical TNM stage, diagnose time, postoperative chemotherapy, and style of operation. Variables that had no significant differences in univariate analysis were not included in the multivariate analysis. Three patients were excluded from the analysis because they died within I month after surgery and they did not receive postoperative chemotherapy.

Abbreviations: PSM, propensity matched; FLOT, docetaxel, oxaliplatin, leucovorin, and 5-fluorouracil; FOLFOX6, oxaliplatin, leucovorin, and 5-fluorouracil. 
Table S2 Univariate and multivariate analysis of survival in patients received preoperative FLOT chemotherapy $(n=45)$

\begin{tabular}{|c|c|c|c|c|c|c|}
\hline \multirow[t]{2}{*}{ Variables } & \multicolumn{2}{|c|}{ Univariate analysis } & \multirow[t]{2}{*}{$P$-value } & \multicolumn{2}{|c|}{ Multivariate analysis } & \multirow[t]{2}{*}{$P$-value } \\
\hline & HR & $95 \% \mathrm{Cl}$ & & HR & $95 \% \mathrm{Cl}$ & \\
\hline $\begin{array}{l}\text { Age (years) } \\
\quad<60 \\
\quad \geq 60\end{array}$ & $\begin{array}{l}\mathrm{I} \\
\mathrm{I} .152\end{array}$ & $0.367 \sim 3.619$ & 0.809 & & & \\
\hline $\begin{array}{l}\text { Gender } \\
\text { Male } \\
\text { Female }\end{array}$ & $\begin{array}{l}1 \\
3.83\end{array}$ & $1.236 \sim 11,866$ & 0.02 & $\begin{array}{l}1 \\
6.322\end{array}$ & $1.75-22.91$ & 0.01 \\
\hline $\begin{array}{l}\text { Lauren classification } \\
\text { Intestinal } \\
\text { Diffuse } \\
\text { Mixed }\end{array}$ & $\begin{array}{l}1 \\
2.773 \\
0.864\end{array}$ & $\begin{array}{l}0.801 \sim 9.601 \\
0.158 \sim 4.729\end{array}$ & 0.167 & & & \\
\hline $\begin{array}{l}\text { Tumor location } \\
\text { Upper third } \\
\text { Middle third } \\
\text { Lower third }\end{array}$ & $\begin{array}{l}\mathrm{I} \\
1.272 \\
1.595\end{array}$ & $\begin{array}{l}0.255 \sim 6.348 \\
0.276 \sim 9.212\end{array}$ & 0.866 & & & \\
\hline $\begin{array}{l}\text { Clinical TNM stage } \\
\text { II } \\
\text { III }\end{array}$ & $\mathrm{I}$ & $0.419 \sim 5.643$ & 0.516 & & & \\
\hline $\begin{array}{l}\text { Diagnose time } \\
2013 \sim 2014 \\
2015 \sim 2016 \\
2017\end{array}$ & $\begin{array}{l}1 \\
0.767 \\
1.256\end{array}$ & $\begin{array}{l}0.195 \sim 3.02 \\
0.243 \sim 6.502\end{array}$ & 0.793 & & & \\
\hline $\begin{array}{l}\text { Style of operation } \\
\text { Total gastrectomy } \\
\text { Subtotal gastrectomy } \\
\text { Distal gastrectomy }\end{array}$ & $\begin{array}{l}1 \\
1.079 \\
0.44\end{array}$ & $\begin{array}{l}0.346 \sim 3.362 \\
0.109 \sim 1.776\end{array}$ & 0.412 & & & \\
\hline $\begin{array}{r}\text { Response } \\
\text { CR+PR } \\
\text { SD+PD }\end{array}$ & $\begin{array}{l}1 \\
5.655\end{array}$ & $1.25 \mathrm{I}-25.58$ & 0.009 & $\begin{array}{l}1 \\
8.21\end{array}$ & $1.66-40.56$ & 0.005 \\
\hline
\end{tabular}

Notes: Adjusted HR (95\%) was adjusted by age, gender, Lauren classification, tumor location, clinical TNM stage, diagnose time, style of operation, and response. Variables that had no significant differences in univariate analysis were not included in the multivariate analysis. Two patients lost the data of response and were excluded from the analysis.

Abbreviations: FLOT, docetaxel, oxaliplatin, leucovorin, and 5-Fluorouracilf; CR, complete response; PR, partial response; SD, stable disease; PD, progressive disease.

\section{Publish your work in this journal}

Cancer Management and Research is an international, peer-reviewed open access journal focusing on cancer research and the optimal use of preventative and integrated treatment interventions to achieve improved outcomes, enhanced survival and quality of life for the cancer patient.
The manuscript management system is completely online and includes a very quick and fair peer-review system, which is all easy to use. Visit http://www.dovepress.com/testimonials.php to read real quotes from published authors. 